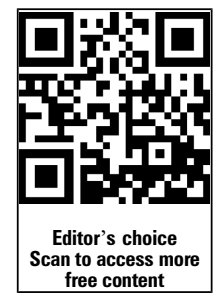

- Additional material is published online only. To view please visit the journal online (http://dx.doi.org/10.1136/ flgastro-2013-100340).

${ }^{1}$ Department of Gastroenterology, Waikato Hospital, Hamilton, New Zealand

${ }^{2}$ Faculty of Medical and Health Sciences, The University of Auckland, Auckland, New Zealand

\section{Correspondence to} Dr James Irwin, Department of Gastroenterology, Waikato Hospital, Pembroke Street, Private Bag 3200, Hamilton 3240, New Zealand; jazirwin@gmail.com

Received 2 May 2013 Revised 13 June 2013 Accepted 15 June 2013 Published Online First 18 July 2013
To cite: Irwin J, Ferguson $R_{\text {, }}$ Weilert $\mathrm{F}$, et al. Frontline Gastroenterology 2014;5:2-9.

\title{
Factors at presentation predictive of a requirement for endoscopic therapy in patients presenting with overt upper gastrointestinal haemorrhage: a retrospective observational study
}

\author{
James Irwin, ${ }^{1}$ Reid Ferguson, ${ }^{2}$ Frank Weilert, ${ }^{1}$ Anthony Smith ${ }^{1}$
}

\begin{abstract}
Introduction In patients with upper

gastrointestinal haemorrhage (UGIH), endoscopic treatment of high-risk lesions reduces mortality.

Performing out of office hours endoscopy places a strain on endoscopy services. This analysis aims to identify factors at presentation associated with lesions requiring endoscopic therapy, allowing triage of those likely to receive benefit from acute out of hours endoscopy.
\end{abstract}

Methods Patients presenting between 17 March 2001 and 12 October 2010 with UGIH had clinical and laboratory features on presentation, endoscopic findings and administered treatment recorded. Patients with known cirrhotic liver disease were excluded. Logistic regression was performed, identifying factors at presentation associated with a requirement of endoscopic therapy (RET), which were then used to create a scoring system predictive of RET.

Results In all, 1492 patients were analysed. The presence on presentation of fresh melaena $(\mathrm{OR}=$ 3.18, $p<0.001)$, fresh haematemesis $(O R=2.13$, $\mathrm{p}<0.001)$, haemoglobin $<130 \mathrm{~g} / \mathrm{L}(\mathrm{OR}=2.65$, $\mathrm{p}<0.001)$, urea $>10 \mathrm{mmol} / \mathrm{L}(\mathrm{OR}=2.10, \mathrm{p}<0.001)$, systolic blood pressure $<100 \mathrm{~mm} \mathrm{Hg}(\mathrm{OR}=1.85$, $p<0.001)$, inpatient status $(O R=1.43, p=0.04)$, $a$ history of peptic ulcer disease $(O R=1.96, p=0.02)$, male sex $(O R=1.45, p=0.01)$, presentation within $8 \mathrm{~h}$ of symptom onset $(O R=1.48, p=0.02)$, coffee ground vomitus $(\mathrm{OR}=0.47, \mathrm{p}=0.004)$ and warfarin use $(O R=0.57, p=0.005)$ were associated with RET. Using a simple scoring system (fresh haematemesis $=2$, fresh melaena $=2$, haemoglobin $<130=2$, urea $>10=1, B P<100=1$, male sex $=1$, history of peptic ulcer disease $=1$ ), a score $\geq 7$ was associated with RET in $45 \%$ of cases and a score $\leq 4$ in $7 \%$.

Conclusions Application of this scoring system when assessing patients presenting with UGIH out of office hours may help predict the likelihood of RET, and aid in the triage of endoscopy. Prospective validation of this score in an external cohort is required.

\section{INTRODUCTION \\ Background}

Upper gastrointestinal haemorrhage (UGIH) is defined as bleeding distal to the upper oesophageal sphincter and proximal to the ligament of Treitz. ${ }^{1}$ Patients with UGIH present with one or more of haematemesis, melaena, hypotension and collapse. In published series, mortality lies between $7 \%$ and $14 \% .^{2-5}$ Incidence figures for UGIH vary between 48-172 per 100000 per year. ${ }^{3}{ }^{6} \mathrm{UGIH}$ is a common cause of presentation to hospital, often requiring inpatient management.

Over the past 30 years gastroscopy has become a routine clinical tool used to investigate and treat UGIH. It enables the diagnosis of the underlying cause of bleeding and the administration of therapeutic haemostasis. Endoscopic therapy in UGIH is used to treat bleeding from gastric and duodenal ulcers, vascular lesions such as Dieulafoy's lesion and oesophageal or gastric varices. Therapeutic options include adrenaline 
injection, haemostatic clip placement, diathermy coagulation, ligation band placement or sclerotherapy injection.

\section{Endoscopic therapy}

Endoscopic therapy provides benefit in UGIH by reducing the physiological consequences of ongoing blood loss at the incident bleed and from episodes of rebleeding. It reduces mortality in UGIH due to peptic ulceration, ${ }^{8}$ and has been shown to reduce rebleeding and mortality in acute variceal bleeding. ${ }^{9} 10$

Patients with UGIH who present to an endoscopy service out of office hours are usually triaged for either acute after-hours endoscopy, or endoscopy delayed until the next day. For patients with UGIH without RET delaying acute gastroscopy until the next day is unlikely to alter outcome. In contrast, for those with RET, emergency endoscopic therapy is associated with a reduction in acute bleeding, risk of rebleeding and mortality.

There is no prospective data demonstrating that early endoscopy reduces objective outcome measures (mortality, requirement of surgery, rebleeding episodes). A retrospective analysis of time to gastroscopy suggests that rates of surgery and rebleeding are reduced in those who undergo endoscopy within $24 \mathrm{~h},{ }^{11}$ and society guidelines recommend performing gastroscopy for higher-risk patients within $24 \mathrm{~h}^{1}{ }^{112}$

\section{AIM}

To define a simple scoring system, using features available on presentation, that will help to identify those patients presenting after office hours with UGIH who are most likely to benefit from acute endoscopy.

\section{DEFINITIONS}

For this study, UGIH was defined as UGIH without evidence in the clinical record or on initial assessment of cirrhotic liver disease. This definition includes patients with variceal bleeding discovered at endoscopy who did not appear to have cirrhotic liver disease on presentation, and so is representative of non-variceal UGIH as assessed at presentation.

RET was defined as the presence at endoscopy of a lesion whose endoscopic treatment is associated with a reduction in mortality or rebleeding. These were peptic ulceration with stigmata of recent haemorrhage (SRH; spurting or oozing blood, a visible vessel or an adherent fresh clot, Forrest classification Ia, Ib, IIa or IIb), ${ }^{13-15}$ an actively bleeding vascular lesion, ${ }^{16}$ or gastric or oesophageal varices. ${ }^{8} 9$ Blood in the upper gastrointestinal tract was not considered RET, given it is not always associated with identification of an endoscopically treatable lesion.

Fresh haematemesis was defined as vomiting red blood, fresh melaena as passing loose maroon stool or loose black stool, old melaena as passing formed black stool and per rectum blood as passing red blood per rectum.

\section{METHODS}

Patient selection

All patients presenting to Waikato Hospital (Hamilton, New Zealand) between 17 March 2001 to 12 October 2010 with UGIH had presenting features, endoscopic diagnosis, presence of SRH and administered treatment recorded prospectively on a dedicated database. Additional clinical and laboratory data at presentation were retrospectively recorded through review of the clinical records by an investigator blinded to the endoscopic findings. For patients with more than one UGIH event during the study period, only the first event was included in the analysis. Patients with a history or clinical evidence of cirrhotic liver disease on presentation and patients who did not have gastroscopy performed within $48 \mathrm{~h}$ of presentation were excluded from the analysis.

Collected datapoints are listed in table 1.

\section{Statistical methods}

Statistical analysis was performed using the $\mathrm{R}$ statistical programming environment. ${ }^{17}$ The Student $t$ test (continuous variables) and Pearson's $\chi^{2}$ test for independence (categorical variables) were used to identify variables crudely associated with RET. Those with a $p$ Value of significance of association $\leq 0.2$ were entered in a stepwise fashion into a multivariate logistic regression model. Variables with independent association with the outcome variable were retained in the model. Continuous variables were converted to categorical variables, using an automated algorithm to choose cut-off values maximising the strength of association between the variable and the outcome while minimising the number of levels in the newly created categorical variable. Significant outlier values (which may disproportionately influence the model) were not searched for as there were no continuous variables in the final model. Interactions between variables were searched for and included in the final model if significant.

Variables included in the final model were combined to form a scoring system associated with RET. Sensitivity and specificity of the score was analysed using receiver operator curve (ROC) analysis. Variable weighting was modified using an automated algorithm to maximise the area under the curve to produce a final scoring system. A simplified system was then created using only the variables most strongly associated with RET in the regression model.

\section{RESULTS}

There were 1851 bleeding events recorded in the database over the study period. Exclusions are shown in figure 1. In all, 911 (61\%) were men and the mean age was 68.3 years. A total of 307 (20.6\%) patients had RET identified at endoscopy. Of these, 35 had oesophageal or gastric varices, 139 had active bleeding associated with either peptic ulcer disease (PUD) or a 
Table 1 Simple association of analysed variables with RET

\begin{tabular}{|c|c|c|c|}
\hline \multicolumn{3}{|l|}{ Variable and type } & \multirow[t]{2}{*}{$\mathrm{p}$ Value } \\
\hline Continuous variables & Mean (no RET) & Mean (RET) & \\
\hline Systolic blood pressure, $\mathrm{mm} \mathrm{Hg}$ & 126.58 & 117.10 & $<0.001$ \\
\hline Haemoglobin, g/L & 101.24 & 92.52 & $<0.001$ \\
\hline Urea, mmol/L & 14.64 & 17.86 & $<0.001$ \\
\hline Diastolic blood pressure, $\mathrm{mm} \mathrm{Hg}$ & 68.48 & 64.20 & $<0.001$ \\
\hline Pulse, beats/min & 88.27 & 91.54 & 0.01 \\
\hline Platelets, $\times 10^{12}$ cells/L & 279.41 & 258.71 & 0.02 \\
\hline Age, years & 68.20 & 68.73 & 0.60 \\
\hline Creatinine, $\mu \mathrm{mol} / \mathrm{L}$ & 126.57 & 123.62 & 0.66 \\
\hline INR & 1.57 & 1.59 & 0.84 \\
\hline Categorical variables & $\mathrm{OR}$ & $\chi^{2}$ statistic & \\
\hline Fresh melaena & 3.08 & 71.29 & $<0.001$ \\
\hline Old melaena & 0.29 & 38.16 & $<0.001$ \\
\hline Coffee ground vomitus & 0.29 & 27.13 & $<0.001$ \\
\hline Fresh haematemesis & 1.67 & 14.12 & $<0.001$ \\
\hline Per rectum bleeding & 0.92 & 2.92 & 0.23 \\
\hline Sex (male) & 1.49 & 8.39 & $<0.001$ \\
\hline Ethnicity: NZ European (reference level) & 1.00 & NA & NA \\
\hline Ethnicity: Maori & 1.24 & 1.62 & 0.20 \\
\hline Year of bleeding event & 1.42 & 6.90 & 0.01 \\
\hline History of peptic ulcer disease & 1.83 & 4.62 & 0.03 \\
\hline Inpatient status & 1.13 & 4.25 & 0.12 \\
\hline Duration of symptoms less than $8 \mathrm{~h}$ before presentation & 1.31 & 3.24 & 0.07 \\
\hline Syncope on presentation & 1.37 & 2.93 & 0.09 \\
\hline Ranitidine use & 2.05 & 4.57 & 0.03 \\
\hline PPI use & 0.78 & 2.48 & 0.12 \\
\hline Warfarin use & 1.28 & 2.37 & 0.12 \\
\hline NSAID or aspirin use & 0.76 & 2.00 & 0.16 \\
\hline NSAID use & 1.19 & 1.67 & 0.20 \\
\hline Clexane use & 1.25 & 0.40 & 0.53 \\
\hline Thrombolysis in past 28 days & 0.96 & 0.27 & 0.60 \\
\hline Unfractionated heparin use & 1.49 & 0.22 & 0.64 \\
\hline Clopidogrel use & 0.66 & 1.21 & 0.27 \\
\hline Aspirin use & 0.48 & 0.98 & 0.32 \\
\hline Dipyridamole use & 0.92 & 0.00 & 0.96 \\
\hline Presence of disseminated cancer & 0.39 & 3.50 & 0.06 \\
\hline Ischaemic heart disease & 1.14 & 0.86 & 0.35 \\
\hline Gastric or oesophageal cancer & 1.15 & 0.83 & 0.36 \\
\hline Chronic renal impairment & 0.00 & 0.78 & 0.38 \\
\hline Diabetes & 1.09 & 0.21 & 0.65 \\
\hline COPD & 1.10 & 0.11 & 0.74 \\
\hline Rheumatoid arthritis & 1.29 & 0.05 & 0.83 \\
\hline Previous stroke & 0.94 & 0.03 & 0.86 \\
\hline Congestive cardiac failure & 1.04 & 0.02 & 0.90 \\
\hline ASA score & 1.08 & 0.67 & 0.96 \\
\hline
\end{tabular}

Variable 'year of bleeding event' defined as a dichotomous variable: ie, either the first or the second half of the study period.

ASA, American Society of Anaesthesiology; COPD, chronic obstructive pulmonary disease; INR, international normalised ratio; NSAID, non-steroidal anti-inflammatory drug; PPI, proton pump inhibitor; RET, requirement of endoscopic therapy.

vascular lesion, 92 had PUD with a visible vessel and 41 had PUD withan adherent fresh clot.

The results of simple association analysis are shown in table 1.
In all, 10 variables retained independent association with RET in the logistic regression model and are listed in the abstract. Optimal cut-off points for conversion of continuous variables to categorical variables 


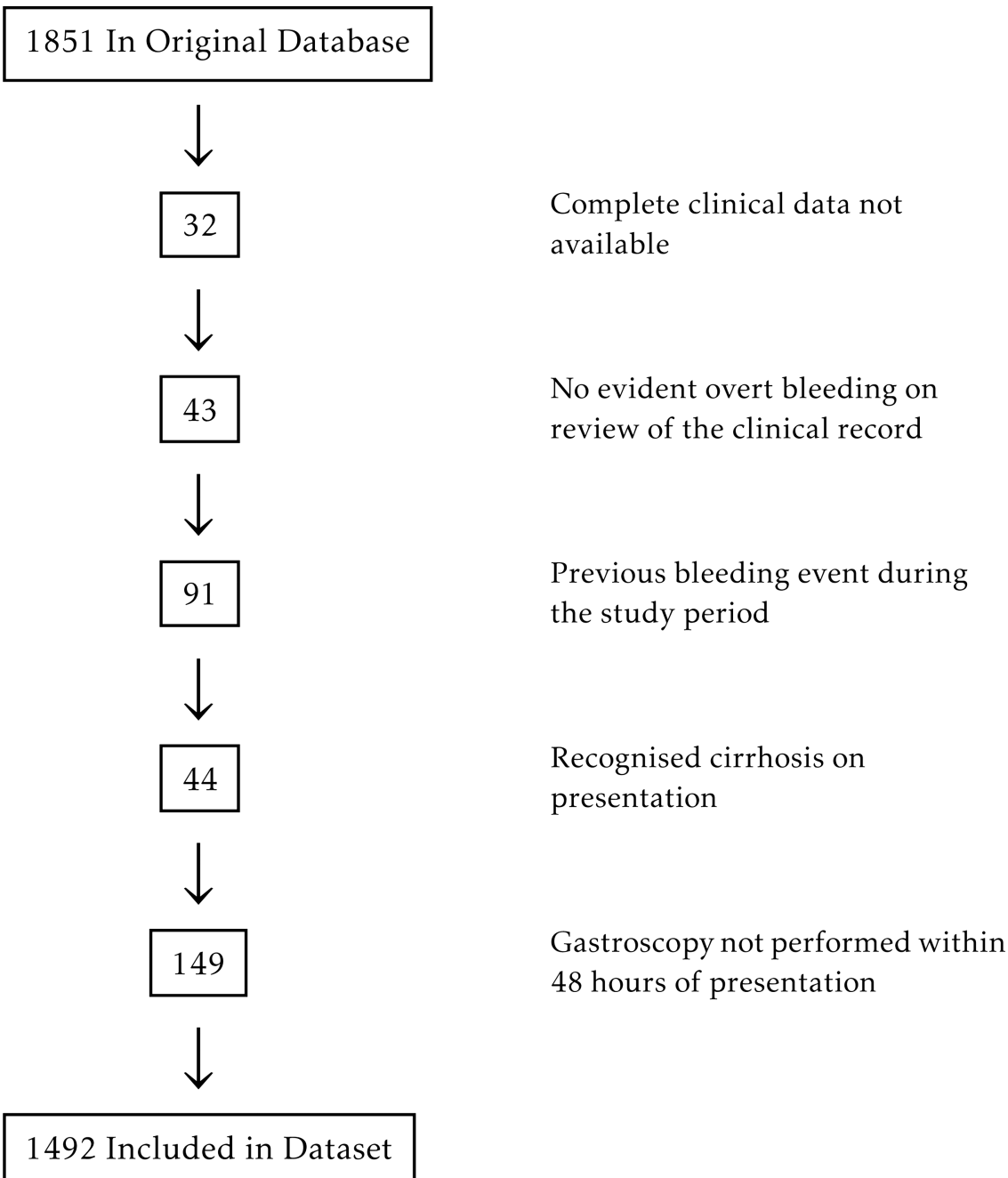

Figure 1 Patient exclusions.

were $100 \mathrm{~mm} \mathrm{Hg}$ for systolic blood pressure (SBP), $10 \mathrm{mmol} / \mathrm{L}$ for serum urea and $130 \mathrm{~g} / \mathrm{L}$ for haemoglobin level.

Table 2 Full and simple scoring systems predictive of RET

\begin{tabular}{lcc}
\hline Variable & Full score & Simple score \\
\hline Fresh melaena & 3 & 2 \\
Fresh haematemesis & 3 & 2 \\
$\mathrm{Hb}<130$ & 2 & 2 \\
$\mathrm{BP} \geq 100 \mathrm{~mm} \mathrm{Hg}$ & 2 & 1 \\
Urea $\geq 10 \mathrm{mmol} / \mathrm{L}$ & 2 & 1 \\
Coffee grounds & -1 & \\
Inpatient status & 2 & \\
Male sex & 1 & 1 \\
History of peptic ulcer disease & 1 & 1 \\
Presentation within $8 \mathrm{~h}$ & 1 & \\
Warfarin use & -1 & \\
Inpatient+fresh haematemesis & -3 & \\
Coffee grounds+presentation within $8 \mathrm{~h}$ & -3 & \\
Maximum score & 17 & \\
\hline BP, blood & &
\end{tabular}

$\mathrm{BP}$, blood pressure; $\mathrm{Hb}$, haemoglobin; $\mathrm{RET}$, requirement of endoscopic therapy.
Two interactions were identified between variables: fresh haematemesis was not associated with RET among inpatients, and for patients presenting within $8 \mathrm{~h}$ of symptom onset presentation with coffee ground vomitus had a strong negative association with RET. The full logistic regression model comprised the following variables and interactions: fresh melaena $(\mathrm{OR}=$ $3.13, \mathrm{p}<0.001)$, fresh haematemesis $(\mathrm{OR}=2.70$ $\mathrm{p}<0.001)$, haemoglobin $(\mathrm{Hb})<130 \quad(\mathrm{OR}=2.76$, $\mathrm{p}<0.001)$, SBP $<100 \mathrm{~mm} \mathrm{Hg}(\mathrm{OR}=1.87, \mathrm{p}<0.001)$, presentation within $8 \mathrm{~h}(\mathrm{OR}=1.57, \mathrm{p}=0.012)$, urea $>10.0 \mathrm{mmol} / \mathrm{L}(\mathrm{OR}=2.05, \mathrm{p}<0.001)$, inpatient status $(\mathrm{OR}=1.92, \mathrm{p}=0.001)$, male sex $(\mathrm{OR}=1.48, \mathrm{p}=0.008)$, history of peptic ulcer disease $(\mathrm{OR}=2.04, \mathrm{p}=0.015)$, coffee ground vomitus $(\mathrm{OR}=0.65, \mathrm{p}=0.131)$, warfarin use $(\mathrm{OR}=0.59, \mathrm{p}=0.009)$, presentation within $8 \mathrm{~h}+$ coffee ground vomitus $(\mathrm{OR}=0.21,0.049)$ and inpatient + fresh haematemesis $(\mathrm{OR}=0.34, \mathrm{p}=0.003)$.

Using ROC analysis a full scoring system and a simplified scoring system were defined optimising association with RET. (table 2, figures 2 and 3) $45 \%$ of those patients with a simplified score $\geq 7$ had RET, compared with $7 \%$ of those with a score $<5$. 

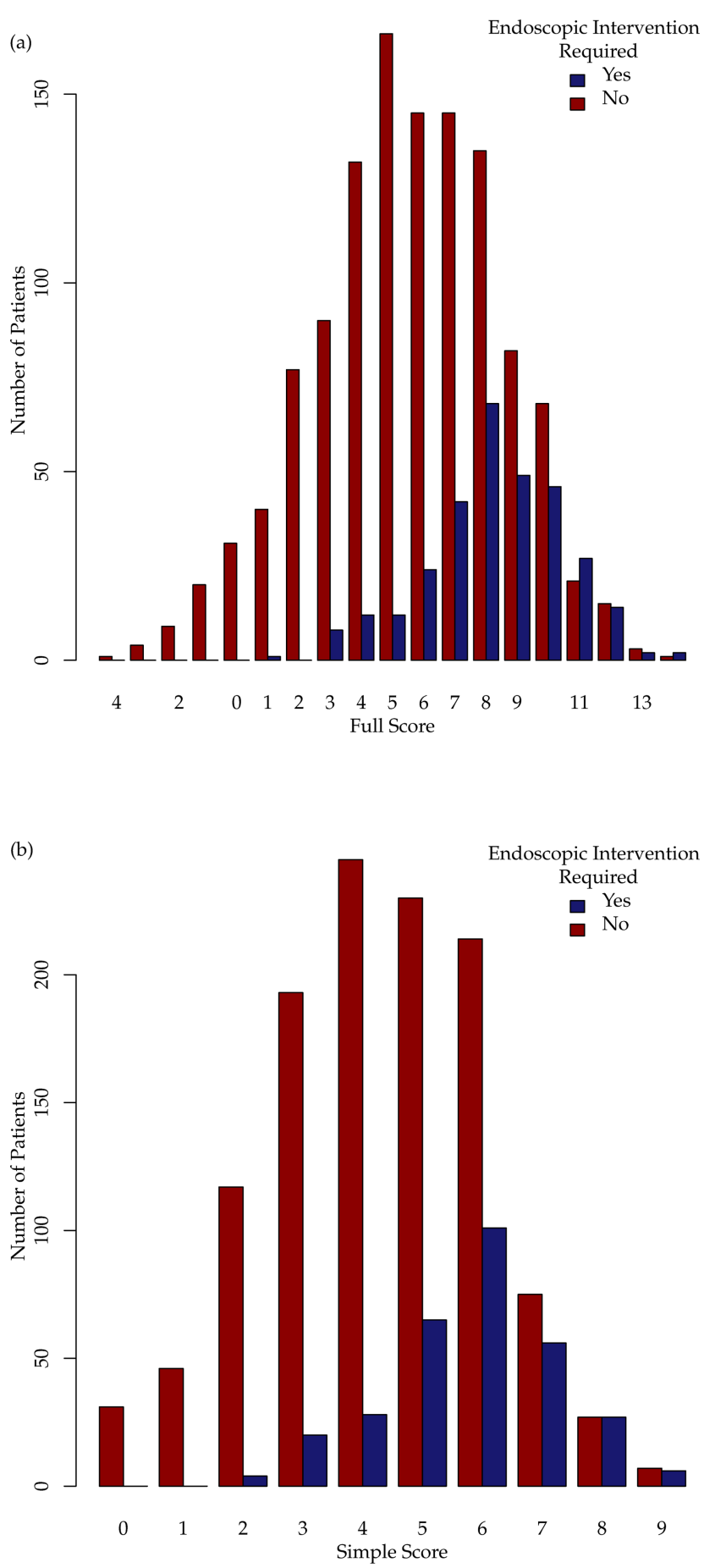

Figure 2 Barplots of the full (a) and simple (b) scoring systems in this cohort, stratified by the presence or absence of RET.

A number of observations were made on subgroup analysis. Duodenal ulcer (DU) was more common in men $(225 / 911 ; 24.7 \%$ of men, $93 / 581 ; 16.0 \%$ of women, $\mathrm{p}<0.001)$. Among patients with duodenal ulceration, inpatients were more likely to have RET at endoscopy $(55 / 79 ; 68 \%$ of inpatients with DU required endoscopic therapy, vs $115 / 239$; $47 \%$ of outpatients with DU, $\mathrm{p}<0.001)$. Peptic ulceration was less common in warfarin users $(72 / 234 ; 30.1 \%$ of warfarin users vs $468 / 1256 ; 37.3 \%$ of non-warfarin users, $\mathrm{p}=0.068$ ), while it was more common in patients with a history of peptic ulceration (43/70; $61 \%$ with history of peptic ulceration vs $497 / 1422$; $35 \%$ without history of peptic ulceration, $\mathrm{p}<0.001$ ).

\section{DISCUSSION}

\section{Analysis of included variables}

This analysis has identified 10 variables on presentation in patients with UGIH independently associated with RET. Mode of presentation (fresh haematemesis, fresh melaena, coffee ground vomiting), low blood pressure, low haemoglobin and presentation within $8 \mathrm{~h}$ of symptom onset are all variables positively or negatively associated with significant luminal blood, or significant blood loss. It is biologically plausible that these variables are associated with the presence of RET at endoscopy.

Serum urea is known to rise in UGIH, and has been previously identified as a marker of severity of gastrointestinal haemorrhage. ${ }^{18} 19$ In our study the optimum discriminatory cut-off for association with RET was $10 \mathrm{mmol} / \mathrm{L}$. Converting the data from a continuous to a categorical variable significantly increased the strength of association of serum urea with RET. This appears to be due to mitigation of the effect on the model of patients with renal impairment and very high urea levels, without RET.

A history of peptic ulceration was associated with RET at endoscopy in our cohort. This association was due to a high proportion of patients with a history of peptic ulceration having a peptic ulcer at endoscopy, and the majority of RET being SRH in peptic ulcer disease.

In previous analyses, those who experienced UGIH while inpatients have had a higher risk of death. ${ }^{5}$ In our cohort rates of diagnosis of peptic ulceration were similar in inpatients and in outpatients. However, in patients with duodenal ulceration there was a much higher proportion of RET in inpatients in comparison to outpatients. There was no significant difference in coagulopathy or platelet count between groups. Duodenal ulceration in inpatients appeared to be more acute and severe, and more likely to have SRH. The observed increased incidence in RET in inpatients was partly due to this phenomenon.

Males are at higher risk of duodenal ulceration, perhaps because of the effect of testosterone and the absence of the effect of oestrogens on mucus production in the proximal bowel. ${ }^{20} 21$ This effect was evident in our dataset.

Finally, warfarin use in this analysis was negatively associated with RET. The coagulopathy that warfarin induces means that clinically significant bleeding may occur from lesser mucosal lesions. Diagnosis of peptic ulcer was made less frequently in warfarin users in this analysis.

\section{Comparison to existing scoring systems}

The Rockall score and the Blatchford score are two clinical tools commonly used for risk assessment at 

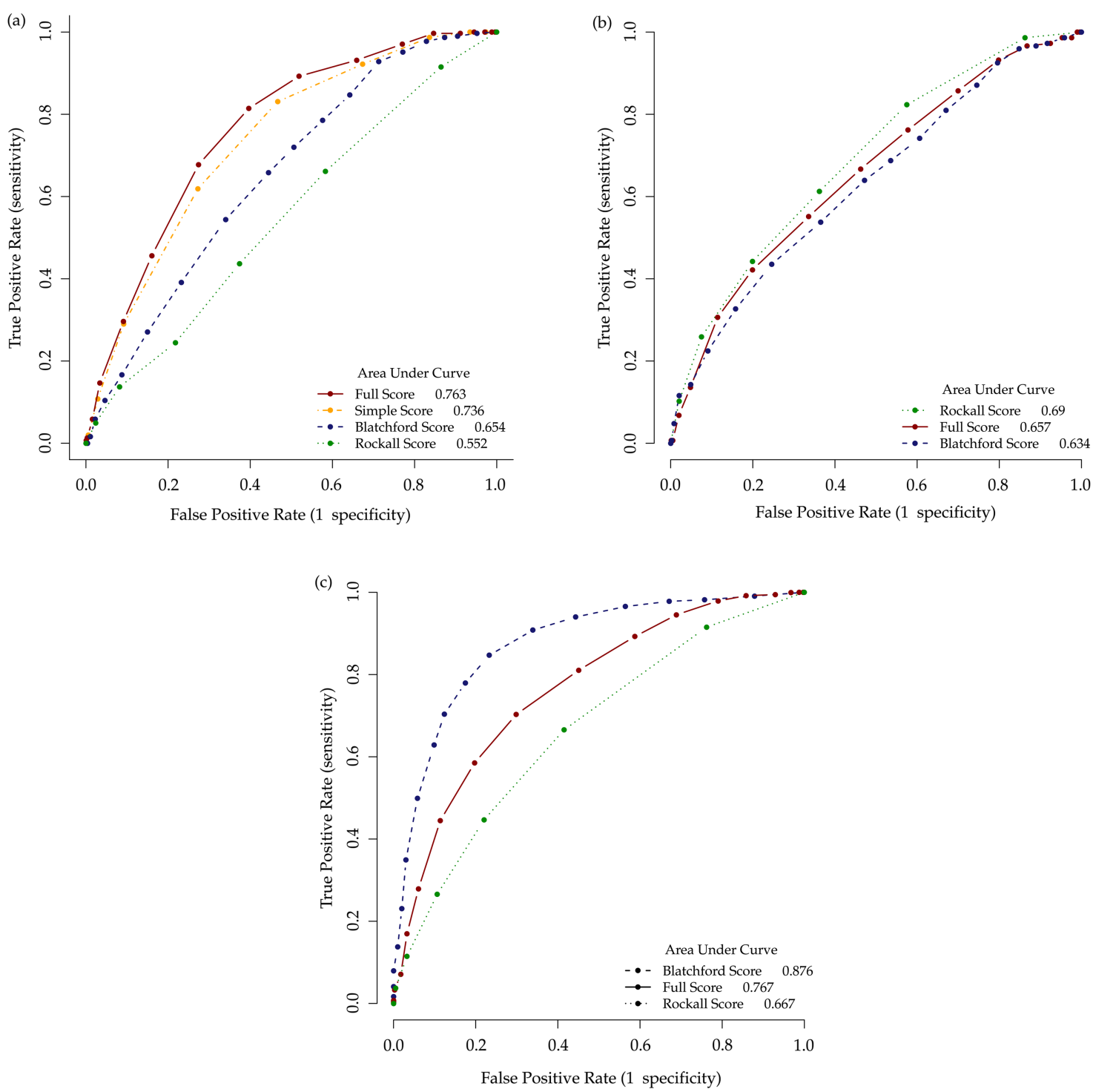

Figure 3 ROC plots of the association of this score, the Rockall Score and the Blatchford Score with RET (a), death (b), and the combined Blatchford outcome (c) respectively, in this cohort.

presentation of patients with UGIH. ${ }^{2} 19$ The Rockall score uses features available on presentation to predict mortality, while the Blatchford score uses features available on presentation to predict the need for in-hospital treatment (defined using a composite endpoint of requirement of blood transfusion, requirement of endoscopic or operative intervention to control bleeding, death, rebleeding, or a substantial fall in haemoglobin). Neither of these scores were designed to assess the likelihood of RET at endoscopy.

As demonstrated in the ROC curves (figure 3) the Blatchford score and the Rockall score had comparatively good association with the respective outcomes for which they were designed. However, they performed less well when the outcome variable was RET. Analysis of the variables included in each score allows some explanation of these differences.

Neither age nor comorbity, major components of the Rockall score, were associated with RET in this study. Risk of death as calculated by the Rockall score does not necessarily correlate with a high likelihood of RET. This is illustrated by the example of a 55 -year-old man without significant comorbidity presenting with fresh melaena and fresh haematemesis, with a high serum urea and a low haemoglobin. This patient is at low risk of death as calculated by the Rockall score, yet is likely to have RET and receive benefit from the administration of endoscopic therapy.

The main differences in variables used by this score and the Blatchford score are that male sex, history of peptic ulceration, early presentation to hospital and inpatient status were associated with RET but were not included in the Blatchford score. Additionally the weighting of predictor variables differed. A low haemoglobin has a lesser weighting in this score, while in the Blatchford score it features strongly. This difference could be considered to be due to the association of a low haemoglobin level with administration 
of blood transfusion, a part of the combined endpoint used in the Blatchford analysis.

Das $e t a^{22}$ designed an artificial neural network (ANN) used to assess on presentation the likelihood of RET in patients with UGIH. Because it requires entry of 21 variables into a predictive neural network, it is unlikely to be used routinely at the bedside in clinical practice.

This analysis identified a number of similar variables to those identified by Das et al: hypotension, fresh haematemesis, male gender and low haemoglobin level. However, three variables with strong association in this study (fresh melaena, a high serum urea and inpatient status) were not included in the ANN. Additionally, a number of variables used in the ANN were analysed and not associated with RET in this study: increasing age, comorbidity (cardiovascular disease, chronic obstructive pulmonary disease (COPD), chronic renal failure, diabetes mellitus) and serum creatinine level. This difference may be a consequence of the analyses being performed on different patient populations, or the use of differing statistical analyses. An ANN identifies potentially complex relationships between predictor variables and outcome, in contrast to logistic regression that only includes predictor variables that have independent association with the outcome variable.

\section{Strengths and limitations of the study}

This study has a number of strengths. Patients were ascertained prospectively, and the number of patients and complete data collection allowed detailed statistical analysis. However, because it is a single centre study the findings are less likely to be generalisable to other patient populations. Secondly, some of the data was collected retrospectively and so was open to the introduction of interpretation bias. This was limited by blinding the data collector to endoscopic findings. Thirdly, there were a number of endoscopists involved in the study, and variation in interpretation of the presence of RET may have introduced bias. Interpretation of the presence of SRH has been shown to vary significantly between endoscopists. ${ }^{23}$ Fourthly, gastroscopy was sometimes performed up to $48 \mathrm{~h}$ after presentation, meaning that some patients who had RET at presentation may not have had this identified at endoscopy because the lesion had healed. ${ }^{14}$ Conversely, intravenous omeprazole treatment was only administered to patients after endoscopic confirmation of a high-risk lesion, and therefore would not have influenced the presence of RET at endoscopy. This is a single derivation cohort, and rigorous confirmation of the identified associations would require prospective validation on an external cohort.

\section{CONCLUSIONS}

The use of this scoring system may aid in the triage of patients presenting with UGIH into those likely and unlikely to have RET at endoscopy. However, the prospective application of this scoring system in an external cohort is required to confirm its accuracy for predicting RET. Studies that have analysed the effect of delay to endoscopy on outcome in UGIH have not clearly identified an optimal timing for acute endoscopy, although guidelines from major societies recommend endoscopy for higher-risk patients within $24 \mathrm{~h}$. Although a high risk of RET does not necessarily translate into benefit from acute out of hours endoscopy, these patients are most likely to have their outcome improved by early interventional endoscopy. We believe that this is the group in whom early endoscopy should be strongly considered.

Acknowledgements We would like to acknowledge the contribution of Carolyn Gibbs, who maintains our database, Steve Holmes who provided valuable support in data analysis, and Jim Brooker, Jason Hill and Melissa Haines who helped collected data for this study.

Contributors JI, RF and AS were responsible for design of the study, data collection and cleaning of data. JI designed and performed the statistical analysis and drafted the paper. JI, AS and FW reviewed the manuscript for publication. JI is guarantor.

Funding This work was kindly supported by the Waikato District Health Board.

Competing interests None.

Provenance and peer review Not commissioned; internally peer reviewed.

Data sharing statement The data from this study can be made available to readers of this journal from the corresponding author.

\section{REFERENCES}

1 Hwang JH, Fisher DA, Ben-Menachem T, et al. The role of endoscopy in the management of acute non-variceal upper GI bleeding. Gastrointest Endosc 2012;75:1132-8.

2 Rockall TA, Logan RF, Devlin HB, et al. Risk assessment after acute upper gastrointestinal haemorrhage. Gut 1996;38:316-21.

3 Van Leerdam ME, Vreeburg EM, Rauws EAJ, et al. Acute upper GI bleeding: did anything change? Time trend analysis of incidence and outcome of acute upper GI bleeding between 1993/1994 and 2000. Am J Gastroenterol 2003;98:1494-9.

4 Yavorski RT, Wong RK, Maydonovitch C, et al. Analysis of 3,294 cases of upper gastrointestinal bleeding in military medical facilities. Am J Gastroenterol 1995;90:568-73.

5 Marmo R, Koch M, Cipolletta L, et al. Predictive factors of mortality from nonvariceal upper gastrointestinal hemorrhage: a multicenter study. Am J Gastroenterol 2008;103:1639-47; quiz 1648.

6 Blatchford O, Davidson LA, Murray WR, et al. Acute upper gastrointestinal haemorrhage in west of Scotland: case ascertainment study. BMJ 1997;315:510-14.

7 Lewis JD, Bilker WB, Brensinger C, et al. Hospitalization and mortality rates from peptic ulcer disease and GI bleeding in the 1990s: relationship to sales of nonsteroidal anti-inflammatory drugs and acid suppression medications. Am J Gastroenterol 2002;97:2540-9.

8 Cook DJ, Guyatt GH, Salena BJ, et al. Endoscopic therapy for acute nonvariceal upper gastrointestinal hemorrhage: a meta-analysis. Gastroenterology 1992;102:139-48. 
9 Infante-Rivard C, Esnaola S, Villeneuve JP. Role of endoscopic variceal sclerotherapy in the long-term management of variceal bleeding: a meta-analysis. Gastroenterology 1989;96:1087-92.

10 Stiegmann GV, Goff JS, Michaletz-Onody PA, et al. Endoscopic sclerotherapy as compared with endoscopic ligation for bleeding esophageal varices. N Engl J Med 1992;326:1527-32.

11 Cooper GS, Chak A, Way LE, et al. Early endoscopy in upper gastrointestinal hemorrhage: associations with recurrent bleeding, surgery, and length of hospital stay. Gastrointest Endosc 1999;49:145-52.

12 Barkun AN, Bardou M, Kuipers EJ, et al. International consensus recommendations on the management of patients with nonvariceal upper gastrointestinal bleeding. Ann Intern Med 2010;152:101-13.

13 Laine L, Peterson WL. Bleeding peptic ulcer. N Engl J Med 1994;331:717-27.

14 Freeman ML. Value of stigmata in decision-making in gastrointestinal haemorrhage. Baillieres Best Pract Res Clin Gastroenterol 2000;14:411-25.

15 Forrest JA, Finlayson ND, Shearman DJ. Endoscopy in gastrointestinal bleeding. Lancet 1974;2:394-7.

16 Baettig B, Haecki W, Lammer F, et al. Dieulafoy's disease: endoscopic treatment and follow up. Gut 1993;34:1418-21.
17 R Development Core Team. R: A language and environment for statistical computing. [Internet]. Vienna, Austria: R Foundation for Statistical Computing; 2011. http://www. R-project.org/

18 Pumphrey CW, Beck ER. Raised blood urea concentration indicates considerable blood loss in acute upper gastrointestinal haemorrhage. Br Med J 1980;280:527-8.

19 Blatchford O, Murray WR, Blatchford M. A risk score to predict need for treatment for upper-gastrointestinal haemorrhage. Lancet 2000;356:1318-21.

20 Aguwa CN. Effects of exogenous administration of female sex hormones on gastric secretion and ulcer formation in the rat. Eur J Pharmacol 1984;104:79-84.

21 László F, Varga C, Montoneri C, et al. Damaging actions of testosterone on cysteamine-induced gastroduodenal ulceration and vascular leakage in the rat. Eur J Pharmacol 1997;337:275-8.

22 Das A, Ben-Menachem T, Farooq FT, et al. Artificial neural network as a predictive instrument in patients with acute nonvariceal upper gastrointestinal hemorrhage. Gastroenterology 2008;134:65-74.

23 Laine L, Freeman M, Cohen H. Lack of uniformity in evaluation of endoscopic prognostic features of bleeding ulcers. Gastrointest Endosc 1994;40:411-17. 